\title{
Analysis of vibronic interactions in the molecules of cross-conjugated ketones
}

\author{
V.V. Kompaneez ${ }^{*}$, and I.A. Vasilieva \\ Moscow State Pedagogical University, 119991 Moscow, Russia
}

\begin{abstract}
We have done quantitative analysis of vibronic parameters of two cross-conjugated $\delta$-dimethylaminoketones. The research shows the influence of $\mathrm{C}-\mathrm{N}$ and $\mathrm{C}=\mathrm{O}$ bonds in the rings, and the radicals with nitro compounds on the vibronic parameters of characteristic bands, which describe the state (vibrations, types of deformation under excitation) of the phenyl ring and the polyene bridge. Results described impact of the substituent's nature on the parameters of intra- and intermolecular interactions presents for the studied compounds.
\end{abstract}

We have done analyses, which interpreting major characteristic vibrational bands crosssubstituted ketones. It shows that ketones like the diphenylpolyenes, one can observe the appearance of the lines in the spectra which corresponding to the change of such specific elements molecules as polyene bridge or aromatic ring.

It is known that frequency bands of compounds with the carbonyl group in six-bonds ring are the same as in the compounds with the open chain (when $\mathrm{C}=\mathrm{O}$ group is located between two methylene groups) [1], however, it known nothing about the intensity of these bands. Therefore, it was interest to produce the comparative analysis of the spectral properties of ketones and diphenylpolyenes at the same time, and quantification of the contribution of intramolecular interactions in the organization of the fine-structure spectra of these molecules. In order to realize such kind if investigations the different methods of selective laser spectroscopy can be used $[2,3]$, in particular vibrational analysis of conjugated absorption and luminescence spectra [4-7].

In this study, the basic osciliation for ketones with general formula $\mathrm{R}_{1,2}=\mathrm{Ph}-\mathrm{CO}-\mathrm{R}_{1}$ (where $\mathrm{R}_{1} \rightarrow(\mathrm{CH}=\mathrm{CH})_{2}-\mathrm{N}\left(\mathrm{CH}_{3}\right)_{2}, \mathrm{R}_{2} \rightarrow \mathrm{CH}_{3}-\mathrm{NC}_{4} \mathrm{H}_{3}-\mathrm{CH}, \mathrm{Ph} \rightarrow\left(\mathrm{HOC}_{6} \mathrm{H}_{6}\right)$ ) were correlated with the interpretation of similar value and substituent frequencies 1,4-diphenylbutadiene with the substituent on the ring $\mathrm{N}\left(\mathrm{CH}_{3}\right)_{2}$ and $\mathrm{NO}_{2}$, respectively (after - DFB3), which spectral properties have been studied previously [8-10]. We shown how band intensities ketones characterizing polyene bridge and the phenyl ring are changes. We selected the first molecule of the ketone with the same substituents as locate in DFB3, left polyene chain in the second molecule of the ketone folds into a five-membered ring $\left(\mathrm{R}_{2}\right)$.

It is shown that the parameters of vibronic spectra of ketone molecules exhibit a high degree of tolerance in the molecules sequence which having the same set of structural elements. It greatly expands the possibilities for use of the fragmented approach to describe the fundamental bands of molecules $[6,7,11-13]$.

Participation ketone molecules in the formation of hydrogen bonds significantly reduces the frequency of the $\mathrm{C}=\mathrm{O}$ (Tab. 1, line 2), conjugate with multiple bonds and aromatic rings

\footnotetext{
*Corresponding author: kompaneez@gmail.com
} 
significantly affect by the position and intensity of the band in the range of $1500-1760 \mathrm{~cm}^{-1}$. The implantation of substituents and representation polyene chain as cycle form with a heteroatom, which containing two multiple bonds, decreases the dipole moment of the molecule. It lead to reduces the intermolecular interaction parameters. When we considering the bands with weak manifestation in the spectra of some luminophors, where $\mathrm{C}-\mathrm{H}$ and $\mathrm{C}=\mathrm{C}$ bonds fluctuations occur, we confirmed that the presence of substitutes and the aromatic rings can be used to enhance the intensity of these bands (see Tab.1, line 1).

Table 1. The charts of parameters intramolecular (FC) and intermolecular (HT) interactions.

\begin{tabular}{|c|c|c|}
\hline Interpretation & Vibration of parameters FC & Vibration of parameters HT \\
\hline $\begin{array}{l}\text { Planar and plane } \\
\text { deformation vibrations } \\
\text { of C-H bonds } \\
\text { substituted aromatic } \\
\text { components at the } \\
\text { double bond. }\end{array}$ & 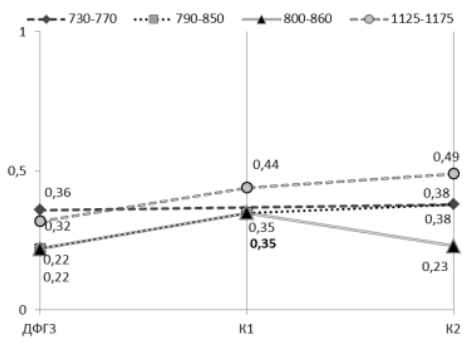 & 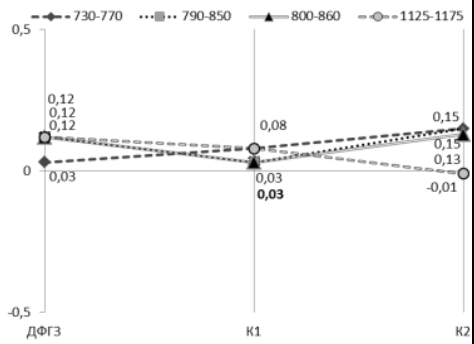 \\
\hline $\begin{array}{c}\text { Deformation } \\
\text { vibrations of } \mathrm{N}-\mathrm{H}, \mathrm{a} \\
\text { manifestation of } \mathrm{C}-\mathrm{N} \\
\text { bond in the cycle, the } \\
\text { manifestation of aryl } \\
\text { nitro compounds } \\
\text { R-NO } \mathrm{NO}_{2} \text {. } \\
\text { Stretching vibrations } \\
\text { of the } \mathrm{C}=\mathrm{C} \text {, coupled } \\
\text { with the } \mathrm{C}=\mathrm{O} \text {. }\end{array}$ & 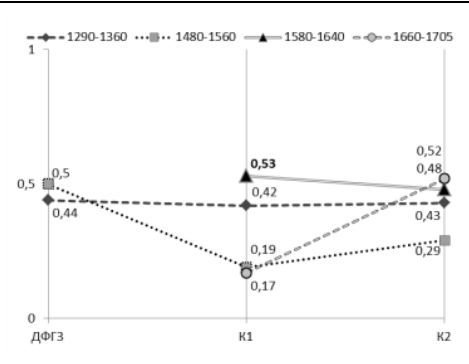 & \\
\hline
\end{tabular}

This work was financially supported by the Russian Foundation for Basic Research, project no. 15-32-21100-mol_a_ved.

\section{References}

1. L.J. Bellamy, The Infrared Spectra of Complex Molecules (Springer, Berlin, 1975)

2. M. Orrit, J. Bernard, R.I. Personov, J. Phys. Chem. 97, 10256 (1993)

3. A.V. Naumov, Physics Uspekhi 56, 605 (2013)

4. A.V. Naumov, N.L. Naumova, I.S. Osad'ko, Opt. Spectrosc. 91, 750 (2001)

5. N.L. Naumova et al., Opt. Spectrosc. 92, 426 (2002)

6. N.L. Naumova et al., Opt. Spectrosc. 98, 535 (2005)

7. N.L. Naumova, I.A. Vasil'eva, I.S. Osad'ko, A.V. Naumov, J. Lumin. 111, 37 (2005)

8. V.V. Kompaneets, I.A. Vasilieva, Bull. RAS: Physics 80, 848 (2016)

9. I.A. Vasil'eva et al., J. of Optical Technology 78, 286 (2011)

10. I.A. Vasilieva, V.V. Kompaneets, Opt. Spectrosc. 114, 60 (2013)

11. I.A. Vasilieva, V.V. Kompaneets, Opt. Spectrosc. 115, 32 (2013)

12. V.V. Kompaneets, I.A. Vasilieva, Opt. Spectrosc. (2016) (to be published)

13. I.A. Vasil'eva, N.A. Voitova, R.N. Nurmukhametov, Opt. Spectrosc. 112, 488 (2012) 